\title{
HACIA UN NUEVO ESQUEMA DE FINANCIACIÓN DE LA UNIVERSIDAD PÚBLICA COLOMBIANA*
}

\author{
Jesús H. Duarte y Carlos Leonardo Villa. \\ Departamento Nacional de Planeación.
}

Los desequilibrios que han conducido a la actual crisis del sistema de financiación de las universidades del Estado no son coyunturales sino estructurales. Estamos afrontando las consecuencias de la incoherencia global de un esquema de financiación en el cual las unidades del sistema no han desarrollado una autonomía financiera correlativa de su autonomía académica y administrativa formal: por un lado, quienes toman decisiones que comprometen el nivel de gasto transfieren a otros la responsabilidad de pagar; por otro lado, quienes asignan recursos lo hacen siguiendo patrones históricos, sin tener en cuenta criterios de gestión, esfuerzo en la generación de recursos propios y eficiencia en el uso de los recursos.

Este documento presenta una visión global acerca de la problemática del financiamiento de la universidad oficial. La primera sección examina las estructuras financieras de la universidad estatal colombiana; la segunda presenta un perfil de la oferta de educación superior. En la tercera, se analiza la organización institucional del sector, especialmente en los aspectos relacionados con la financiación. La cuarta sección contiene una revisión crítica del modelo actual de financiación, el cual se caracteriza por una asignación negociada que no atiende criterios de eficiencia y calidad. Finalizaremos con las líneas generales de un nuevo esquema que buscaría canalizar parte de la financiación a través de la demanda y diversificar sus fuentes para que las instituciones estatales aboguen por los recursos de acuerdo con indicadores de calidad y eficiencia, a fin de sustentar su autonomía y realizar su función de largo plazo.

\section{Los recursos destinados a la universidad}

En 1995 el gasto público total en educación superior en el país representó el $0.76 \%$ del $\mathrm{PIB}^{9}$. Los aportes directos de la nación fueron el $0.53 \%$ del PIB ( $\$ 449.567$ millones de 1996), mientras los recursos propios de las universidades fueron $0.23 \%$ PIB (\$197.653 millones de 1996). Dentro de estos últimos se cuentan los aportes de los departamentos $(0.04 \%$ del PIB), los ingresos por derechos académicos y venta de servicios $(0.15 \%$ del PIB), y los aportes de otras entidades nacionales como Colciencias y el lcetex $(0.01 \%$ del PIB). Los restantes ingresos provienen de recursos del balance y de operaciones financieras. A las universidades nacionales correspondió $0.36 \%$ del PIB y a las territoriales ${ }^{10}$ $0.40 \%$ del PIB (ver cuadros Nos. 1 y 2 ).

\footnotetext{
* Las opiniones aquí expresadas no comprometen al Departamento Nacional de Planeación, entidad para la cual laboran los autores. Agradecemos los valiosos aportes de Javier Sáenz Obregón, jefe de la División de Educación del DNP, especialmente en el análisis institucional del sector, y de César Caballero, asesor de la Dirección del DNP.

${ }^{9}$ A comienzos de la presente década el gasto público en educación superior en Colombia había alcanzado un nivel equivalente al $0.57 \%$ del PIB, inferior al de otros países de América Latina como Costa Rica con $1.66 \%$ y Chile con $0.64 \%$. Sin embargo, en los últimos años el gasto público en este nivel educativo ha incrementado su participación, y en 1996 llegó al 0.77\% del PIB. Fuentes: PNUD, Informe sobre Desarrollo Humano 1993-1995, y División de Educación, Ministerio de Hacienda y Crédito Público.

${ }^{10}$ La diferencia entre universidades nacionales y territoriales carece de valor operativo, desde el punto de vista de la cobertura y la financiación; es una distinción formal. Esta distinción surge de la diferencia de nivel territorial de las corporaciones legislativo-administrativas que crean las instituciones. La distinción se traduce 
Cuadro No. 1

Universidades públicas en Colombia

Estructura de ingresos y participación de las fuentes en el PIB y en el PGN 1995

(Millones de pesos de 1996)

\begin{tabular}{|l|r|r|r|r|r|}
\hline \multicolumn{1}{|c|}{ Fuentes } & U. Nales & U. Territoria. & Total & \%PIB & \%PGN \\
\hline Aporte directo de la nación & 247.192 & 202.375 & 449.567 & $0.53 \%$ & $1.9 \%$ \\
Recursos departamentales & - & 31.171 & 31.171 & $0.04 \%$ & $0.1 \%$ \\
Recursos propios & 62.126 & 63.698 & 125.824 & $0.15 \%$ & $0.5 \%$ \\
Otros(*) & - & 40.658 & 40.658 & $0.05 \%$ & $0.2 \%$ \\
Total & 309.318 & 337.902 & 647.220 & $0.76 \%$ & $2.8 \%$ \\
\%PIB & $0.36 \%$ & $0.40 \%$ & $0.76 \%$ & & \\
\%PGN & $1.32 \%$ & $1.44 \%$ & $2.76 \%$ & & \\
& & & & & \\
Aportes indirectos de la nación (\&) & & & & & \\
Aportes Colciencias & & & 9,035 & $0.01 \%$ & $0.04 \%$ \\
Aportes vía lcetex & & & 1,418 & $0.002 \%$ & $0.01 \%$ \\
\hline
\end{tabular}

Fuente: División de Educación, DGPN, Ministerio de Hacienda y Crédito Público. Ejecutado 1995.

$\left(^{*}\right)$ 'Otros" incluye recursos municipales, del balance y operaciones financieras. (\&) Los aportes indirectos de la nación aparecen contabilizados dentro de los recursos propios. Esos aportes indirectos vía Colciencias e Icetex no se discriminan aquí entre universidades nacionales y departamentales debido a que no se dispone de la información pertinente.

Cuadro No. 2

Universidades públicas en Colombia

Estructura de ingresos y participación de las fuentes

en el PIB 1991-1996

(Millones de pesos de 1996)

\begin{tabular}{|c|c|c|c|c|c|c|c|}
\hline $\begin{array}{c}\text { EN MILLONES } \\
\text { CONSTANTES } \\
\text { DE } 1996\end{array}$ & NACIONALES & TERRITORIA & TOTAL & $\begin{array}{c}\text { COSTO } \\
\text { PREGRADO(*) }\end{array}$ & $\begin{array}{c}\% \text { PIB } \\
\text { NALES }\end{array}$ & $\begin{array}{c}\text { \%PIB } \\
\text { TERRIT. }\end{array}$ & $\begin{array}{c}\text { \%PIB } \\
\text { TOTAL }\end{array}$ \\
\hline \multirow{3}{*}{$\begin{array}{c}1991 \text { otros }(\&) \\
\text { nación } \\
\text { total }\end{array}$} & 27.619 & 72.749 & 100.368 & & $0.04 \%$ & $0.10 \%$ & $0.14 \%$ \\
\hline & 166.535 & 135.295 & 301.830 & & $0.24 \%$ & $0.19 \%$ & $0.43 \%$ \\
\hline & 194.154 & 208.044 & 402.198 & 281.538 & $0.28 \%$ & $0.30 \%$ & $0.57 \%$ \\
\hline $1992 \operatorname{otros}(\&)$ & 32763 & 111.108 & 143.871 & & $0.04 \%$ & $0.15 \%$ & $0.20 \%$ \\
\hline nación & 178.399 & 118.587 & 296.986 & & $0.24 \%$ & $0.16 \%$ & $0.41 \%$ \\
\hline total & 211.162 & 229.695 & 440.857 & 308.600 & $0.29 \%$ & $0.31 \%$ & $0.60 \%$ \\
\hline 1993 otros(\&) & 52.195 & 101.534 & 153.729 & & $0.07 \%$ & $0.13 \%$ & $0.20 \%$ \\
\hline nación & 195.927 & 148.242 & 344.168 & & $0.25 \%$ & $0.19 \%$ & $0.45 \%$ \\
\hline total & 248.121 & 249.776 & 497.898 & 348.528 & $0.32 \%$ & $0.32 \%$ & $0.65 \%$ \\
\hline $1994 \operatorname{otros}(\&)$ & 57.440 & 125.158 & 182.598 & & $0.07 \%$ & $0.15 \%$ & $0.22 \%$ \\
\hline nación & 230.082 & 212.448 & 442.531 & & $0.28 \%$ & $0.26 \%$ & $0.54 \%$ \\
\hline total & 287.522 & 337.606 & 625.128 & 437.590 & $0.35 \%$ & $0.42 \%$ & $0.77 \%$ \\
\hline 1995 otros(\&) & 62.126 & 135.527 & 197.653 & & $0.07 \%$ & $0.16 \%$ & $0.23 \%$ \\
\hline
\end{tabular}

en grados de compromiso de esos niveles de la organización territorial con la financiación de las universidades. 


\begin{tabular}{|c|c|c|c|c|c|c|c|c|}
\hline & nación & 247.192 & 202.375 & 449.567 & & $0.29 \%$ & $0.24 \%$ & $0.53 \%$ \\
\hline & total & 309.318 & 337.902 & 647.220 & 453.054 & $0.36 \%$ & $0.40 \%$ & $0.76 \%$ \\
\hline 199 & otros(\&) & 75.791 & 174.439 & 250.230 & & $0.09 \%$ & $0.20 \%$ & $0.28 \%$ \\
\hline & nación & 251.454 & 185.777 & 437.230 & & $0.28 \%$ & $0.21 \%$ & $0.49 \%$ \\
\hline & total & 327.245 & 360.216 & 687.461 & 481.222 & $0.37 \%$ & $0.41 \%$ & $0.77 \%$ \\
\hline
\end{tabular}

Fuente: División de Educación, DGPN, Ministerio de Hacienda. 1991-1995, ejecutado; 1996, asignado. PIB, Umacro-DNP.

$\left({ }^{*}\right)$ El costo del pregrado se estimó en un $70 \%$ del costo total de las universidades. (\&) Los otros recursos de las universidades departamentales incluyen los recursos propios, los aportes territoriales y los recursos del balance.

Colciencias financió, a través de los programas nacionales de ciencia y tecnología y de formación de recursos humanos, proyectos de las universidades públicas colombianas por un valor de $\$ 9.035$ millones de pesos ${ }^{11}$. Esta fuente de financiación del orden nacional provee un porcentaje significativo de los recursos propios de las universidades públicas, diferentes a los ingresos por derechos académicos ${ }^{12}$.

Además de los recursos de inversión que el presupuesto nacional asigna directamente a las instituciones de educación superior y de los aportes indirectos de Colciencias, la nación, a partir de 1996, destina recursos adicionales a proyectos de inversión que éstas presentan, los cuales se administran a través del Fodesep ${ }^{13}$. En 1996 el Fondo asignó recursos por $\$ 12,800$ millones de pesos a instituciones públicas de educación superior ${ }^{14}$.

\section{Estructura de ingresos de las universidades}

En 1995, en la estructura de ingresos de las universidades públicas de carácter nacional, la nación destinó en promedio el $80 \%$ de los gastos totales, mientras que las instituciones financian con recursos propios el restante $20 \%$ (ver cuadro No. 3). Debe anotarse que la participación del sector central es mayor en las universidades nacionales diferentes de la Nacional, pues esta última genera más recursos propios que todas ellas juntas ${ }^{15}$.

En 1995, las universidades territoriales recibieron de la nación recursos para cubrir el $60 \%$ de sus gastos totales. Los aportes de los departamentos sólo cubren el $9 \%$ de esos gastos $^{16}$. Los recursos propios alcanzan a financiar el $19 \%$ de los gastos, y el restante

\footnotetext{
${ }^{11}$ Colombia ha alcanzado un valor en el gasto de investigación y desarrollo de US $\$ 227.0$ millones representando el $0.31 \%$ PIB. De estos, US $\$ 37$ millones constituyen el aporte nacional a través de Colciencias, es decir, el $16 \%$ del gasto total en lyD. Ecopetrol, Telecom, las empresas industriales y comerciales del Estado, ministerios e institutos financian lo restante. Ver Conpes 2848, "Seguimiento a la política nacional de ciencia y tecnología", Santafé de Bogotá, 1996.

${ }_{12}$ Colciencias aportó el $40 \%$ de los gastos que las universidades estatales hicieron en investigación en 1995.

${ }^{13}$ El Fodesep, Fondo de Desarrollo de la Educación Superior, se creó como una entidad de economía mixta que debe servir de mecanismo de financiación de proyectos de inversión en universidades públicas y privadas. El gobierno nacional ha dado un impulso significativo a este Fondo que puede constituirse en una opción para financiar proyectos de desarrollo institucional y pedagógico, así como de promoción de la calidad de la oferta de este nivel educativo.

${ }^{14}$ El Fodesep da prioridad a proyectos que contemplan la cooperación con otras instituciones públicas o privadas y con el sector productivo, así como a los que expanden la oferta de educación superior en las universidades de menor desarrollo relativo del sistema universitario y en las zonas de frontera.

${ }^{15}$ En 1995, la Universidad Nacional generó $\$ 36.000$ millones frente a $\$ 25.000$ millones generados por todas las demás universidades nacionales juntas.

${ }_{16}$ Deben destacarse, sin embargo, los casos de las universidades Distrital y Cundinamarca, en las cuales los entes territoriales concurren con el $63 \%$ y $52 \%$, respectivamente, del total de los ingresos. Por el 
$12 \%$ proviene de diversas fuentes, como los recursos del balance, las operaciones financieras y los aportes de los municipios, entre otras.

Cuadro No.3

Universidades del Estado

Estructura de ingresos 1995

\begin{tabular}{|c|c|c|c|c|}
\hline & NACIÓN & PROPIOS & DEPTALES. & OTROS \\
\hline $\begin{array}{l}\text { NACIONALES } \\
\text { U. Nacional } \\
\text { U. del Cauca } \\
\text { U.P.N. } \\
\text { U. de Caldas } \\
\text { UPTC-Tunja } \\
\text { U. de Córdoba } \\
\text { U.T. del Chocó } \\
\text { U.T.de los Llanos } \\
\text { U.T. de Pereira } \\
\text { U. Popular del Cesar } \\
\text { U.S. de Neiva } \\
\text { U. de la Amazonia } \\
\text { Unisur } \\
\text { TOTAL NACIONALES } \\
\text { TERRITORIALES } \\
\text { U. de Antioquia } \\
\text { U. de Atlántico } \\
\text { U. de Cartagena } \\
\text { U. de La Guajira } \\
\text { U. de Magdalena } \\
\text { U. de Nariño } \\
\text { U. FCO de P. Santander } \\
\text { U. de Pamplona } \\
\text { U. del Quindío } \\
\text { U.l. de Santander } \\
\text { U. de Sucre } \\
\text { U. del Tolima } \\
\text { U. del Valle } \\
\text { U. de Cundinamarca } \\
\text { U. Distrital } \\
\text { TOTAL TERRITORIALES } \\
\text { TOTAL UNIVERSIDADES }\end{array}$ & $\begin{array}{l}78 \% \\
78 \% \\
80 \% \\
83 \% \\
89 \% \\
93 \% \\
87 \% \\
76 \% \\
95 \% \\
90 \% \\
77 \% \\
83 \% \\
33 \% \\
80 \% \\
\\
69 \% \\
91 \% \\
78 \% \\
61 \% \\
69 \% \\
81 \% \\
56 \% \\
68 \% \\
60 \% \\
88 \% \\
54 \% \\
60 \% \\
43 \% \\
9 \% \\
15 \% \\
60 \% \\
69 \%\end{array}$ & $\begin{array}{c}22 \% \\
22 \% \\
20 \% \\
17 \% \\
11 \% \\
7 \% \\
13 \% \\
24 \% \\
5 \% \\
10 \% \\
23 \% \\
17 \% \\
67 \% \\
20 \% \\
\\
16 \% \\
2 \% \\
10 \% \\
7 \% \\
23 \% \\
19 \% \\
44 \% \\
30 \% \\
30 \% \\
8 \% \\
16 \% \\
21 \% \\
20 \% \\
38 \% \\
17 \% \\
19 \% \\
20 \% \\
\end{array}$ & $\begin{array}{c}0 \% \\
0 \% \\
0 \% \\
0 \% \\
0 \% \\
0 \% \\
0 \% \\
0 \% \\
0 \% \\
0 \% \\
0 \% \\
0 \% \\
0 \% \\
0 \% \\
\\
5 \\
4 \% \\
0 \% \\
8 \% \\
8 \% \\
0 \% \\
0 \% \\
2 \% \\
4 \% \\
4 \% \\
15 \% \\
17 \% \\
3 \% \\
52 \% \\
63 \% \\
9 \% \\
5 \%\end{array}$ & $\begin{array}{c}0 \% \\
0 \% \\
0 \% \\
0 \% \\
0 \% \\
0 \% \\
0 \% \\
0 \% \\
0 \% \\
0 \% \\
0 \% \\
0 \% \\
0 \% \\
0 \% \\
10 \% \\
3 \% \\
12 \% \\
24 \% \\
0 \% \\
0 \% \\
0 \% \\
0 \% \\
6 \% \\
0 \% \\
16 \% \\
2 \% \\
34 \% \\
0 \% \\
6 \% \\
12 \% \\
6 \%\end{array}$ \\
\hline
\end{tabular}

Fuente: División de Educación, DGPN. Ministerio de Hacienda y Crédito Público. Ejecutado 1995.

Como lo señala la Dirección de Crédito Público del Ministerio de Hacienda ${ }^{17}$, el caso de las universidades territoriales demuestra la complejidad del proceso de descentralización en Colombia, pues son instituciones creadas, administradas y dependientes de las entidades territoriales $\mathrm{y}$, sin embargo, reciben del presupuesto nacional más recursos que de dichas entidades territoriales. Uno de los más graves problemas de este esquema radica en el divorcio entre la autoridad territorial que crea el gasto y la instancia que tiene la posibilidad de financiarlo, es decir, la nación, lo cual le

contrario, a las universidades del Valle, Francisco de Paula Santander, Cartagena y Nariño, los entes territoriales respectivos no aportan más del $4 \%$ de los ingresos.

17 Dirección de Crédito Público del Ministerio de Hacienda, Informe a la Comisión de Racionalización del Gasto Público. Citado por Caballero, César. "Financiamiento de Universidades Públicas". Documento de trabajo, 1996. 
genera a esta un déficit recurrente, que tiene que resolver todos los años. Para 1996 este déficit era de unos $\$ 41 \mathrm{mil}$ millones de pesos. Existe desequilibrio entre el compromiso de la nación y el de los entes territoriales, a pesar de ser los departamentos y municipios los que se benefician con la educación superior y participan en la creación del gasto.

El esfuerzo por generar recursos propios ha crecido desde la década de los 80 . En ese lapso el peso de los recursos propios generados por las instituciones pasó del $14.3 \%$ al $20 \%$ en el caso de las nacionales y del 12 al $19 \%$ en las territoriales ${ }^{18}$. Sin embargo, esa mejoría no ha resuelto el problema de la alta dependencia de las estructuras financieras de la universidad pública con respecto al nivel central. En particular, el pago de derechos de matricula sigue teniendo poco peso en el total de las fuentes de recursos. En los 80, las matriculas y derechos académicos representaron un $44 \%$ de los recursos propios y el $3.6 \%$ de los recursos totales, mientras en 1995 significaron aproximadamente el 30\% de los propios y el $6 \%$ de los totales ${ }^{19}$, lo cual indica un crecimiento modesto en volumen y un decrecimiento en su participación entre las fuentes de recursos propios ${ }^{20}$.

Es ilustrativo comparar esta estructura de ingresos de las universidades públicas con la de las privadas: estas originan el $87 \%$ de los recursos totales en venta de servicios de docencia (matriculas y derechos académicos) y de servicios de extensión e investigación. Las matrículas generan el $70 \%$ de los ingresos ${ }^{21}$, en tanto que la universidad pública depende de los aportes de la nación, que financian el $69 \%$ de los gastos estatales (cuadro No. 3).

Cuadro No. 4

Universidades públicas en Colombia

Estructura de gastos 1995

\begin{tabular}{|l|c|c|c|c|}
\hline ENTIDAD & \%SERV. PERS. & \%GASTOS GRALES. & \%INVERSIÓN & \%DEUDA \\
\hline U. Nacional & $77 \%$ & $4 \%$ & $19 \%$ & $0.0 \%$ \\
U. del Cauca & $80 \%$ & $17 \%$ & $3 \%$ & $0.0 \%$ \\
U.P.N. & $75 \%$ & $11 \%$ & $14 \%$ & $0.0 \%$ \\
U. de Caldas & $84 \%$ & $7 \%$ & $9 \%$ & $0.0 \%$ \\
U.P.T.C. & $86 \%$ & $11 \%$ & $3 \%$ & $0.0 \%$ \\
U. Córdoba & $75 \%$ & $14 \%$ & $11 \%$ & $0.0 \%$ \\
U. Chocó & $74 \%$ & $11 \%$ & $15 \%$ & $0.0 \%$ \\
U. Llanos & $60 \%$ & $12 \%$ & $28 \%$ & $0.0 \%$ \\
U. Pereira & $82 \%$ & $8 \%$ & $10 \%$ & $0.0 \%$ \\
U. Cesar & $77 \%$ & $12 \%$ & $11 \%$ & $0.0 \%$ \\
U. Neiva & $73 \%$ & $12 \%$ & $15 \%$ & $0.0 \%$ \\
\hline
\end{tabular}

18 Molina, Carlos y Cifuentes, Ariel, Sistema Universitario Estatal: componente financiero, Bogotá, Fedesarrollo, 1989, p. 25 y cálculos UDS-DEC. Merecen especial mención, entre las regionales, las universidades del Quindío y Francisco de Paula Santander, cuyo recursos alcanzan el 35\% de sus ingresos totales, y entre las nacionales, las universidades Surcolombiana, Pedagógica Nacional y de Caldas que generan cerca del $30 \%$ de sus recursos.

19 "Los ingresos por matrículas de pregrado son el 4\% de los ingresos totales en 1995.

20 Según estudio de Hugo López en 1992 las matriculas eran el 4.6\% de los ingresos totales. Ver La educación superior en Colombia: oferta y demanda; mercado laboral y problemas financieros y de información, p. 10. Carlos Cuartas encontró que las universidades municipales y departamentales mostraron una política más clara de recuperación de costos a través de las matrículas que las nacionales entre 1980 y 1992. Ver Mejoramiento de la eficiencia e indicativa de asignación y desempeño de la universidad oficial, En: Misión Nacional para la modernización de la Universidad Pública, Estudio de base No. 1, p.229-230.

${ }^{21}$ Ascun, "Documento de Trabajo No. 9: Reunión técnica preparatoria de la conferencia regional sobre políticas y estrategias para la transformación de la educación superior en América Latina y el Caribe”. 


\begin{tabular}{|c|c|c|c|c|}
\hline U. Amazonia & $69 \%$ & $13 \%$ & $18 \%$ & $0.0 \%$ \\
\hline Total Nacionales & $78 \%$ & $7 \%$ & $15 \%$ & $0.0 \%$ \\
\hline U. Antíoquia & $80 \%$ & $12 \%$ & $5 \%$ & $3.0 \%$ \\
\hline U. Atlántico & $86 \%$ & $10 \%$ & $3 \%$ & $1.5 \%$ \\
\hline U. Cartagena & $82 \%$ & $9 \%$ & $5 \%$ & $3.9 \%$ \\
\hline U.La Guajira & $58 \%$ & $3 \%$ & $32 \%$ & $7.3 \%$ \\
\hline U. Magdalena & $72 \%$ & $17 \%$ & $9 \%$ & $2.1 \%$ \\
\hline U. Nariño & $87 \%$ & $6 \%$ & $3 \%$ & $4.0 \%$ \\
\hline U.F.P. Santander & $98 \%$ & $2 \%$ & $0 \%$ & $0.2 \%$ \\
\hline U. Pamplona & $77 \%$ & $19 \%$ & $1 \%$ & $3.0 \%$ \\
\hline U. Quindio & $78 \%$ & $8 \%$ & $10 \%$ & $4.1 \%$ \\
\hline U.I.S. & $94 \%$ & $4 \%$ & $1 \%$ & $1.3 \%$ \\
\hline U. Sucre & $72 \%$ & $8 \%$ & $18 \%$ & $2.0 \%$ \\
\hline U. Tolima & $79 \%$ & $10 \%$ & $11 \%$ & $0.0 \%$ \\
\hline U. Valle & $57 \%$ & $8 \%$ & $23 \%$ & $11.6 \%$ \\
\hline U. Distrital & $67 \%$ & $12 \%$ & $19 \%$ & $2.4 \%$ \\
\hline U. Cundinamarca & $74 \%$ & $8 \%$ & $18 \%$ & $0.0 \%$ \\
\hline Total Territoriales & $74 \%$ & $10 \%$ & $11 \%$ & $4.8 \%$ \\
\hline Total & $76 \%$ & $9 \%$ & 13 & 2.5 \\
\hline
\end{tabular}

Fuente: División de Educación, DGPN, Ministerio de Hacienda y Crédito Público, ejecutado 1995.

\section{Estructura de gastos}

En la estructura de gastos de las instituciones, el funcionamiento representa alrededor del $85 \%$, dejando para la inversión una porción residual y no sistemática. Dentro de los gastos de funcionamiento de las universidades del Estado tienen gran peso los servicios personales: en las nacionales constituyen el $78 \%$ y en las territoriales el $74 \%$ (cuadro No. 4). Por su parte, las universidades nacionales dedican más recursos a inversión, el 15\%, mientras que las territoriales sólo pueden destinar el $11 \%$. Las plantas docentes representan el $62 \%$ de los costos totales. Esta composición de los gastos revela una limitada capacidad operativa que afecta las condiciones pedagógicas y las posibilidades de mejoramiento y expansión.

Es pertinente mencionar que en las universidades privadas la docencia absorbe sólo el $60 \%$ de los gastos de funcionamiento, lo cual representa el $50 \%$ de los gastos totales. Por otra parte, para inversión estas instituciones dedican el $25 \%$ de sus recursos totales ${ }^{22}$.

\section{El costo por estudiante}

En la década de los años 80 , el costo unitario por estudiante creció a una tasa del $1.8 \%$ real anual ${ }^{23}$. En lo corrido de la presente década el costo unitario ha crecido a una tasa del $6 \%$ real anual. Hay dos factores que han determinado el crecimiento acelerado ${ }^{24}$ de ese indicador: el estancamiento en el número de estudiantes y el aumento en el costo de la planta.

\footnotetext{
22 Ibid.

${ }^{23}$ Molina, op cit. p. 19-20, cuadro 4.

24 El envejecimiento de la planta y la imprevisión para cubrir el valor de pensiones y cesantías, y los incrementos saláriales basados en el Decreto 1444 son factores señalados por Hugo López como las causas del crecimiento acelerado de los costos totales y por estudiante desde 1993. Op. cit. 10.
} 
En un análisis de corte transversal se evidencia una disparidad entre las universidades del Estado con respecto al costo por estudiante. El grado de complejidad en la oferta académica es un factor que debe tenerse en cuenta. Entre las universidades con alto grado de complejidad y las de bajo la diferencia en el costo unitario es de \$1.6 millones, significativo si se tiene en cuenta que el costo promedio por estudiante en Colombia es de $\$ 3.0$ millones $^{25}$. Los factores asociados a la complejidad introducen costos fijos importantes, tanto por la escala como por la diversidad y nivel tecnológico de las condiciones espaciales y logísticas de esos programas.

El indicador de relación alumno/docente, que en la actualidad es de 13.5 en promedio, también es relevante para explicar la diferencia de comportamiento de los costos unitarios. En comparación con las universidades que presentan un alta relación alumno/docente (22), las de baja (11) muestran un costo por estudiante mayor en $\$ 2$ millones. De hecho, la relación alumno/docente está fuertemente correlacionada con el carácter territorial: las universidades regionales presentan sistemáticamente una relación alumno/docente más alta. Esta cifra indica un potencial de mejoramiento de la eficiencia a través de la elevación de la relación alumno/docente promedio.

Las universidades territoriales tienden a presentar costos unitarios menores que las nacionales. Este hecho puede reflejar varios factores: la no previsión ni contabilización de los aportes a los fondos pensiónales y de cesantías; una utilización más intensa de la capacidad instalada y la presencia de programas a distancia. Por otra parte, no existe correlación entre carácter territorial y salario promedio, lo cual impide atribuir bajos costos por estudiante en estas instituciones a regímenes saláriales más racionales. Sin embargo, es necesario mejorar los sistemas de información a fin de establecer con mayor precisión los indicadores de eficiencia, pues la información disponible sobre el sector es insuficiente e inexacta.

\section{Tipos de programas académicos ofrecidos ${ }^{26}$}

En Colombia se ha presentado un aumento modesto de la tasa de cobertura bruta de la educación superior. En 1990, la tasa de cobertura era 13.7\% y en 1995 había alcanzado el $14.7 \%{ }^{27}$.

En la universidad colombiana existe una gran heterogeneidad en los perfiles institucionales. Sin embargo, puede señalarse una tendencia común a las instituciones públicas y privadas de educación superior. En 1995, los programas de pregrado constituyen el $94.1 \%$ de la matrícula; las maestrías y doctorados no alcanzan el $2 \%$ de la matrícula (cuadro No. 5). El bajo porcentaje de estudiantes en programas de postgrado está asociado al débil desarrollo relativo del país en el campo de la investigación científica y tecnológica, y al atraso en la conformación de comunidades académicas. Este fenómeno es, a su vez, consecuencia del bajo porcentaje de profesores universitarios con formación de postgrado y de los bajos niveles de inversión de las universidades en aquellos rubros requeridos para la formación postgraduada, tales como bibliotecas, computadores y laboratorios.

\footnotetext{
${ }^{25}$ Cifras en pesos de 1996.

${ }^{26}$ Esta sección contó con la apreciable colaboración de Julio César Jiménez, profesional especializado de la División de Educación del DNP.

${ }^{27}$ Al comparar con otros países en desarrollo, la tasa de escolarización de la educación superior colombiana es baja. Calculada como el cociente de la matrícula total sobre la población entre 18 y 24 años, para 1990 , Argentina, Chile y Venezuela habían alcanzado tasas de escolarización de educación superiores del $40.8 \%$, $20.7 \%$ y $29.5 \%$ respectivamente. En ese mismo año Francia había logrado una tasa de escolarización del $39.7 \%$ y Estados Unidos en 1991 tenía una tasa de escolarización de $76.2 \%$. Fuente: Unesco, Statistical Yearbook, 1993.
} 
En el nivel de postgrado, la oferta de las instituciones universitarias privadas es el $66.9 \%$ del total nacional, dos veces la de las públicas. No obstante, la matrícula privada de este nivel se concentra en las especializaciones con $70.5 \%$ del total, mientras en doctorados sólo tiene el 3.9\% (cuadros Nos. 5 y 6 ).

En cuanto a la distribución por áreas del conocimiento, las áreas de mayor complejidad (ciencias agropecuarias, ingenierías y ciencias de la salud) alcanzan sólo el $37 \%$ de la matrícula de pregrado (cuadro No. 5). Esta situación es grave, ya que éstas constituyen las áreas que mayor aporte podrían hacer al desarrollo tecnológico y productivo del país. Por el contrario, en las carreras de ciencias administrativas y económicas, con programas de muy variado nivel de calidad, se concentró la tercera parte del total de alumnos matriculados en 1995 (cuadro No. 5).

Geográficamente, la oferta se concentra en Bogotá, donde está el $45 \%$ de los programas; le siguen Medellín, Bucaramanga, Cali y Barranquilla. Estas cinco ciudades tienen el $75 \%$ de la oferta de educación superior. Este alto nivel de centralización de la oferta tiene efectos negativos como la reducción de las oportunidades de acceso a la educación superior de los estudiantes de ciudades pequeñas y zonas rurales, así como debilidades en cuanto a la vinculación de la educación superior a los procesos de producción y desarrollo de las regiones.

La universidad privada se ha expandido acelerada y desordenadamente. Entre 1960 y 1993 se multiplicó por 14 el número total de universidades de carácter privado ${ }^{28}$. Proliferaron instituciones sin condiciones para ofrecer educación superior de calidad. En su gran mayoría, los nuevos cupos se crearon en horario nocturno: el $45 \%$ de estudiantes de pregrado en las universidades privadas está matriculado en la jornada nocturna.

Cuadro No. 5

Perfil de oferta instituciones de educación superior públicas y privadas

\begin{tabular}{|l|r|r|r|r|r|}
\hline \multicolumn{2}{|c|}{ DISTRIBUCION DE LA OFERTA POR NIVELES Y PROGRAMAS } & \multirow{2}{*}{ Totales } \\
\hline PREGRADO & \multicolumn{2}{|c|}{ Pública } & \multicolumn{2}{c|}{ Privada } & \multicolumn{1}{c|}{ Total } \\
PRE & 206.874 & $94.1 \%$ & 416.582 & $94 \%$ & $\mathbf{9 4 \%}$ \\
Técnica Profesional & 4.240 & $1.9 \%$ & 29.761 & $5 \%$ & \\
Tecnología & 40.866 & $18.6 \%$ & 52.795 & $11.9 \%$ & $14 \%$ \\
Universitaria & 161.768 & $73.6 \%$ & 334.026 & $75.5 \%$ & $75 \%$ \\
POSTGRADO & 12.912 & $5.9 \%$ & 26.122 & $5.9 \%$ & $\mathbf{6 \%}$ \\
Especialización & 9.427 & $4.3 \%$ & 22.523 & $5.1 \%$ & $5 \%$ \\
Maestría & 3.411 & $1.6 \%$ & 3.596 & $0.8 \%$ & $1 \%$ \\
Doctorado & 74 & $0.0 \%$ & 3 & $0.0 \%$ & $0 \%$ \\
PROGRAMAS & & & & & \\
Ciencias agropecuarias & 9.536 & $4.3 \%$ & 4.507 & $1.0 \%$ & $2 \%$ \\
Artes & 3.089 & $1.4 \%$ & 14.127 & $3.2 \%$ & $3 \%$ \\
\hline
\end{tabular}

${ }^{28}$ A nivel internacional pueden identificarse dos modalidades de expansión de la oferta de la educación superior. Una se basó en el crecimiento de las instituciones existentes, lo cual permitió proteger las tradiciones académicas y ampliar su ámbito de influencia, absorbiendo la demanda creciente. La otra fue la vía seguida por Colombia: proliferación de instituciones. Es evidente que, desde el punto de vista de las particularidades y la lógica de producción del bien 'educación superior", esta última era la vía más fácil, pero también la más costosa socialmente, debido a sus evidentes limitaciones para garantizar resultados de calidad. 


\begin{tabular}{|l|r|r|r|r|r|}
\hline Ciencias económicas y adtivas & 49.828 & $22.7 \%$ & $37.2 \%$ & $32 \%$ & \\
Ciencias humanas & 2.642 & $1.2 \%$ & 1.716 & $0.4 \%$ & $1 \%$ \\
Ingenierías & 62.510 & $28.4 \%$ & 112.627 & $25.4 \%$ & $26 \%$ \\
Ciencias básicas & 10.044 & $4.6 \%$ & 3.041 & $0.7 \%$ & $2 \%$ \\
Ciencias de la salud & 20.709 & $9.4 \%$ & 38.983 & $8.8 \%$ & $9 \%$ \\
Licenciaturas (Pedagogía) & 44.665 & $20.3 \%$ & 42.827 & $9.7 \%$ & $13 \%$ \\
Ciencias sociales & 16.763 & $7.6 \%$ & 60.243 & $13.6 \%$ & $12 \%$ \\
TOTAL & $\mathbf{2 1 9 . 7 8 6}$ & $\mathbf{1 0 0 \%}$ & $\mathbf{4 4 2 . 7 0 4}$ & $\mathbf{1 0 0 \%}$ & $\mathbf{1 0 0 \%}$ \\
& & & & & \\
\hline
\end{tabular}

Fuente: ICFES—Estadísticas de la Educación Superior 1995

Cuadro No. 6

Comparación entre los perfiles de la oferta instituciones de educación superior (IES) públicas privadas

\begin{tabular}{|c|c|c|c|c|c|}
\hline \multirow{2}{*}{ Niveles } & \multicolumn{2}{|c|}{$\begin{array}{c}\text { Inst.Educ. Superior } \\
\text { Públicas }\end{array}$} & \multicolumn{2}{|c|}{$\begin{array}{c}\text { Inst.Educ. Superior } \\
\text { Privadas }\end{array}$} & \multirow{2}{*}{ total } \\
\hline & $\begin{array}{c}\text { No de } \\
\text { Estudiantes }\end{array}$ & $(\%)$ & $\begin{array}{c}\text { No de } \\
\text { Estudiantes }\end{array}$ & $(\%)$ & \\
\hline PREGRADO & 206.874 & $33 \%$ & 416.582 & $67 \%$ & 623.456 \\
\hline Técnica profesional & 4.240 & $13 \%$ & 29.761 & $88 \%$ & 34.001 \\
\hline Tecnología & 40.866 & $44 \%$ & 52.795 & $56 \%$ & 93.661 \\
\hline Universitaria & 161.768 & $33 \%$ & 334.026 & $67 \%$ & 495.794 \\
\hline POSTGRADO & 12.912 & $33 \%$ & 26.122 & $67 \%$ & 39.034 \\
\hline Especialización & 9.427 & $30 \%$ & 22.523 & $71 \%$ & 31.950 \\
\hline Maestría & 3.411 & $49 \%$ & 3.596 & $51 \%$ & 7.007 \\
\hline $\begin{array}{l}\text { Doctorado } \\
\text { PROGRAMAS }\end{array}$ & 74 & $96 \%$ & 3 & $4 \%$ & 77 \\
\hline Ciencias agropecuaria & 9.536 & $68 \%$ & 4.507 & $32 \%$ & 14.043 \\
\hline Artes & 3.089 & $18 \%$ & 14.127 & $82 \%$ & 17.043 \\
\hline Ciencias económ. y adtiva & 49.828 & $23 \%$ & 164.633 & $77 \%$ & 214.461 \\
\hline Ciencias humanas & 2.642 & $61 \%$ & 1.716 & $39 \%$ & 4.358 \\
\hline Ingenierías & 65.510 & $36 \%$ & 112.627 & $64 \%$ & 175.137 \\
\hline Ciencias básicas & 10.044 & $77 \%$ & 3.041 & $23 \%$ & 13.085 \\
\hline Ciencias de la salud & 20.709 & $35 \%$ & 38.983 & $65 \%$ & 59.692 \\
\hline Licenciaturas (Pedag.) & 44.665 & $51 \%$ & 42.827 & $49 \%$ & 87.492 \\
\hline Ciencias sociales & 16.763 & $22 \%$ & 60.243 & $78 \%$ & 77.006 \\
\hline TOTAL & 219.786 & $33 \%$ & 442.704 & $67 \%$ & 662.490 \\
\hline
\end{tabular}

Fuente: ‘cfes- Estadísticas de la Educación Superior 1995

En las instituciones de educación superior privadas se concentra el $67 \%$ de la matrícula de educación superior. El alto porcentaje de participación del sector privado en la oferta de educación superior es un rasgo característico de nuestro sistema educativo. Sin embargo, es preocupante que la gran mayoría de las instituciones privadas de educación superior no reúnan los requisitos mínimos de calidad y buena parte de ellas no cuente con docentes idóneos, con programas rigurosos y con la infraestructura requerida

\footnotetext{
* Se encontraron algunas inconsistencias entre los cuadros consolidados del anuario estadístico 1995 del Icfes.

"Se encontraron algunas inconsistencias entre los cuadros consolidados del anuario 
para brindar una educación de calidad. De otra parte, con pocas excepciones, se trata de instituciones docentes que no desarrollan procesos de investigación y extensión. Es evidente que ante una demanda creciente y la debilidad de los mecanismos de vigilancia y control del Estado, debilidad que se ha intensificado con la autonomía que les otorgó la Ley 30 de 1992, parte de la responsabilidad de esta situación le cabe a las universidades públicas y privadas de calidad, las cuales no han realizado esfuerzos significativos por ampliar su cobertura.

Al caracterizar la oferta, debe tenerse en cuenta un fenómeno que afecta en general la calidad. Los docentes de la educación superior poseen una formación débil. Incluyendo la universidad privada y la pública, así como los profesores de planta y de cátedra, en 1995 sólo el $2.3 \%$ tenía titulo de doctor, el $12.6 \%$ tenía maestría, el $19.7 \%$ eran especialistas, el $48.8 \%$ tenía titulo profesional, y los demás - $16.7 \%$--no tenía siquiera título profesional universitario; se trata de licenciados, tecnólogos y técnicos profesionales.

\section{Organización institucional del sector}

Asociada a la multiplicidad de entidades que hacen parte de la organización institucional de la educación superior existen diversas fuentes de financiamiento y mecanismos de asignación, los cuales aplican diferentes criterios de asignación, en general no basados en indicadores, y que hacen bastante complejo el manejo del sector. Para mayor claridad, esquematizamos a continuación las competencias de las entidades que se relacionan, ya sea de manera directa o indirecta con las instituciones de educación superior.

\begin{tabular}{|l|l|}
\hline \multicolumn{1}{|c|}{ INSTITUCION } & \multicolumn{1}{c|}{ COMPETENCIA } \\
\hline Mesu & \multicolumn{1}{c|}{ - Proponer políticas de financiamiento al gobierno nacional } \\
- No tiene competencias en cuanto al financiamiento de la \\
educación superior. Rector de la política educativa nacional. \\
- Constituir el Sistema Nacional de Información de la educación \\
superior, insumo fundamental para la toma de decisiones de \\
asignación de recursos \\
- Definir los aportes de la nación para gastos de funcionamiento \\
de las universidades nacionales y territoriales. \\
- Elaborar en conjunto con las universidades nacionales el pre- \\
supuesto de inversión de estas entidades. \\
- Administra y centraliza todos los recursos de crédito estu- \\
diantil en el país. \\
- Fomento y financiación a grupos, proyectos y recursos huma- \\
nos de investigación de universidades y centros (ver anexo \\
Icetex
\end{tabular} - Fo.4).

Es oportuno presentar algunas observaciones sobre estas competencias y su cumplimiento.

\footnotetext{
${ }^{29}$ Las universidades gozan de autonomía. Constitución Política, art. 69; Ley 30 de 1992, arts. 3 y 28.

Digitalizado por RED ACADEMICA
} 
El Consejo Nacional de Educación Superior -Cesu— organismo vinculado al Ministerio de Educación Nacional, con funciones de coordinación, planificación, recomendación y asesoría, tiene entre sus competencias la de proponer políticas al gobierno nacional. El Cesu no ha abordado el tema del financiamiento y hasta el momento no ha formulado recomendaciones sobre este tema. En general, el Cesu dedica demasiado tiempo a asuntos de trámite, lo cual no ha permitido que asuma a cabalidad su labor de asesoría al gobierno nacional en la definición de políticas para la educación superior.

El Ministerio de Educación Nacional no tiene competencias directas sobre el financiamiento, pero es el rector de la política educativa nacional. En el pasado ha tenido una participación marginal en la definición de políticas de financiamiento y de criterios para la asignación de recursos.

De las funciones del Icfes, la más importante para la toma de decisiones sobre la asignación y distribución de recursos para la educación superior es la referida a la creación de un Sistema Nacional de Información. El propio Conpes en 1995 ordenó al Icfes la implantación de dicho sistema ${ }^{30}$. Al respecto es poco lo que se ha avanzado, hasta el punto de no existir ni el sistema ni un cronograma para su implantación y, mucho menos, la información que se esperaba se proporcionaría a la sociedad colombiana y al Estado acerca de la eficiencia, equidad, cobertura y calidad del servicio de la educación superior. Mientras no se cuente con información adecuada es imposible que las entidades del sector desarrollen políticas de financiamiento ligadas a los resultados de las universidades.

Aunque este punto se desarrolla en el siguiente capitulo, cabe señalar aquí que la asignación de recursos de funcionamiento por parte del Ministerio de Hacienda no obedece a criterios objetivos acerca de la calidad, eficiencia y esfuerzo presupuestal de las universidades. El presupuesto se asigna en forma inercial y mediada por la negociación política.

Los recursos de inversión de las universidades que son manejados por el Departamento Nacional de Planeación son, cada vez, más escasos. Esta situación se va a mantener en la medida en que las prioridades del sector están en el desarrollo de la educación básica. Al igual que sucede con el Ministerio de Hacienda, no se dispone de la información necesaria acerca de las universidades para distribuir estos recursos con criterios técnicos.

El Icetex tiene una cobertura baja: en 1995 benefició el $6.1 \%{ }^{31}$ del total de alumnos matriculados en la educación superior, y sólo pudo atender el $35.7 \%$ de las solicitudes nuevas para crédito de pregrado. A nivel de postgrado atendió el $95 \%$ de la demanda total. En cuanto a la recuperación de la cartera, el Icetex ha tenido un buen desempeño, en comparación con programas similares de otros países. En 1995 sus préstamos en mora presentaron el $13.9 \%$ del total y en 1996 el $13.2 \%{ }^{32}$. Cabe señalar que el otorgamiento de créditos por parte del Icetex no tiene en cuenta las características de las universidades en cuanto a su calidad o eficiencia.

\footnotetext{
30 Documento Conpes №. 2781 de 1995, "Educación superior: recursos humanos para el bienestar y la competitividad".

${ }^{31}$ En 1995 benefició a 39.326 estudiantes de pregrado y 6.709 de postgrado.

32 Información suministrada por Icetex. Enero 1997.

Digitalizado por RED ACADEMICA
} 
El financiamiento de Colciencias no es directamente a las universidades sino a investigadores, grupos académicos o programas de calidad de estas. Es la única institución del sector que tiene criterios rigurosos y transparentes de asignación, por medio de procesos serios de evaluación de las propuestas presentadas.

Los escasos recursos de financiación de proyectos de inversión manejados por el Fodesep no han sido distribuidos con el rigor necesario. A diferencia de lo que ocurre con el financiamiento de proyectos por parte de Colciencias, hasta el momento no se cuenta con un proceso de evaluación lo suficientemente calificado, como tampoco con una sistematización adecuada de los indicadores y su ponderación para la asignación de recursos a los proyectos, una vez estos son evaluados.

Si bien se ha avanzado en relación con la autonomía financiera y administrativa de las universidades públicas existe todavía una serie de problemas que obstaculizan la gestión ágil y flexible, requerida para el cabal cumplimiento de sus propósitos académicos. La Ley 30 de 1992 autorizó a las universidades como entidades autónomas financieramente, con la atribución de manejar su presupuesto de acuerdo con sus funciones académicas, lo cual les permite ejecutar y modificar el presupuesto de manera más ágil que los establecimientos públicos $^{33}$. En la práctica, estas posibilidades de autonomía en el manejo financiero no han sido suficientemente aprovechadas por las universidades, las cuales siguen con un régimen de gestión financiera excesivo. Ejemplo de esto fue la reestructuración en 1993 del régimen orgánico de la Universidad Nacional, en el cual las posibilidades de flexibilización que abrió la Ley 30 no fueron plenamente reconocidas.

De otra, la autonomía de las universidades territoriales se ha visto mediada por el manejo político regional que ha conducido a una diversidad de regímenes laborales y a la creación de gastos que no consultan la dinámica real de los ingresos de las instituciones y han generado desequilibrios financieros graves. La universidad debe ser autónoma, no sólo con respecto a la nación sino a las presiones políticas regionales que distorsionan su manejo autónomo. Es la otra cara de la autonomía: la que muestra la necesidad de asumir la autonomía de manera responsable, como una facultad que impone la obligación de responderle a la sociedad.

En conclusión, las instituciones del sector no están cumpliendo, en general, con las funciones que les competen en relación con el financiamiento de las universidades. De otra parte, con la excepción de Colciencias, el sistema de asignación de recursos no responde a criterios transparentes y objetivos. Existen tres grandes problemas que explican esta situación. En primer lugar, la ausencia de una dirección que defina y vele por el cumplimiento de las políticas de asignación de recursos del sector. En segundo lugar, la necesidad de establecer y poner en funcionamiento criterios racionales y objetivos en la asignación de recursos todavía no ha sido cabalmente asumida por las instituciones responsables del financiamiento de la educación superior. Por último, la ausencia de la información necesaria para el diseño de indicadores sobre el funcionamiento de las universidades, que hace imposible la toma de decisiones objetivas en la distribución de los recursos.

\footnotetext{
${ }^{33}$ Ley 30 de 1992, Título Tercero, capítulo 1, especialmente articulo 57. Ver el comentario y la doctrina que sobre ese articulo traen Noguera, Camilo y Linares, Patricia, El proceso de construcción de las bases de la educación superior, p. 85-91.
} 


\section{El modelo actual de asignación de recursos}

\section{Situación actual de asignación de recursos}

En Colombia opera un proceso de asignación negociada de los recursos de la nación. Este tipo de procesos no se basa en criterios objetivos acerca de las características institucionales, las actividades o los resultados alcanzados por las entidades. Estos procesos normalmente son aplicados por Estados con una débil capacidad institucional y que no cuentan con sistemas de información y evaluación adecuados ${ }^{34}$.

Las decisiones presupuestales están mediadas políticamente. Las instituciones se ven obligadas a buscar padrinazgo político o a utilizar otros mecanismos extrauniversitanos para obtener recursos. Esa práctica elimina a la eficiencia, pues desliga el financiamiento del logro de resultados. Los efectos negativos desde el punto de vista de la calidad, la eficiencia y el concepto de universidad son evidentes.

El modelo inercial negociado es el método más limitado de financiación: carece de incentivos a la eficiencia, por la razón anotada; impide la reasignación ágil de los recursos, pues contempla controles burocráticos estrictos a asignaciones detalladas y rígidas; inhibe la sensibilidad institucional frente a las señales del entorno, pues la fuente de los recursos es independiente de dinámicas de la producción y la sociedad y, lo que tal vez es más grave, impide la autonomía efectiva de las universidades.

Además, con la generalización de las restricciones fiscales en todo el mundo, este modelo dejó de ser viable. Si, como lo planteó Gómez Buendía ${ }^{35}$, la universidad pública desea conservar una función de regulación de la calidad del sistema y una participación importante en el sector, un esquema de financiación y toma de decisiones más estable, autónomo y diverso que le permita obtener recursos para su expansión y cualificación.

En la sección relativa a las características de la oferta señalamos la heterogeneidad de las instituciones estatales. El modelo de financiación actual es inequitativo, además, porque no tiene en cuenta esa diversidad de niveles de complejidad académica, tipos de programas y características regionales. Se asignan recursos sin atender a la productividad académica y científica, a la calidad o a los programas de investigación y extensión.

Otro rasgo negativo del modelo actual es el castigo a la generación de recursos propios. Una universidad como la Nacional, por citar un caso, que genera cerca del $33 \%$ de los recursos del sistema, ve a menudo cómo se dispone de sus rentas, mediante la reducción de los aportes de la nación para funcionamiento. Mientras tanto, universidades que no incrementan sus rentas propias son premiadas con aumentos en el aporte nacional para el mismo rubro. Este fenómeno desincentiva la generación de recursos

\footnotetext{
${ }^{34}$ Banco Mundial, La enseñanza superior, Washington, sf. Albretch, Douglas y Ziderman, Adrian, Funding Mechanisms for Higher Education, Washington, WBDP 153, 1992. De los mismos autores, Deferred Cost Recovery for Hiher Education, Washington, WBDP 137, 1991. Williams, Gareth, Changing patterns of finance Hernando Gómez Buendía sustentó esta tesis en los años 80 y anticipó el crecimiento desmesurado de la oferta barata y de mala calidad si el mecanismo de financiación no se fortalecía con fuentes privadas (estudiantes y empresas) y otras alternativas financieras. Finanzas Universitarias, 1984. Carlos Cuartas también atribuye al congelamiento de las matrículas las limitadas posibilidades de expansión cualitativa y cuantitativa. Además critica el criterio de liquidación de la matrícula que no se basa en el costo de oportunidad ni en los costos reales de operación de las instituciones. En mejoramiento de la eficiencia financiera. p. 229.in higher education, Buckingham: SRHE-Open University Press, 1992.
} 
propios y estimula prácticas de ocultamiento de los ingresos a través de fundaciones y otros mecanismos, lo cual hace aún menos transparente el sistema ${ }^{36}$.

El modelo que opera en Colombia es, además, inequitativo desde el punto de vista de las porciones de la población que están disfrutando de subsidios para acceder a este nivel educativo. Diferentes investigadores ${ }^{37}$ han demostrado que, dado que este esquema de financiamiento asigna el subsidio directamente a las instituciones en lugar de hacerlo a los estudiantes, es un mal instrumento de focalización de los subsidios. El $70 \%$ de los beneficiarios de ese subsidio pertenece a los quintiles de ingreso 4 y 5 , que son los de más altos ingresos, cuyas familias, por tanto, están en capacidad de financiar los costos de la educación de sus hijos.

El sistema educativo establece filtros que impiden el acceso de estudiantes de estratos populares: la mala calidad de la educación básica a la que pueden acceder los estudiantes de esos estratos, la imposibilidad de sufragar los gastos de sostenimiento estudiantil y a la necesidad de trabajar para sostener la familia. Es este el cuello de botella para el acceso de las más pobres a la educación superior: e alto costo de oportunidad: durar 5 años sin percibir ingresos.

El argumento tradicional a favor de la gratuidad de la educación superior oficial ha revelado su falta de validez. Según ese argumento el costo de la matrícula es el factor que determina silos miembros d los estratos populares ingresan o no a la universidad. Sin embargo, el subsidio a la oferta y la gratitud terminaron transfiriendo un monto importante de recursos a los estratos más altos, sin favorecer el acceso de los estratos bajos.

Cuadro No. 7

Distribución de subsidios y asistencia a la educación superior por quintiles de ingreso 1992

\begin{tabular}{|c|c|c|c|c|}
\hline \multirow{2}{*}{ Quintil } & $\begin{array}{c}\text { DISTRIBUCION } \\
\text { DE SUBSIDIOS }\end{array}$ & \multicolumn{3}{|c|}{ ASISTENCIA A LA EDUCACION SUPERIOR } \\
\cline { 2 - 5 } & $\%$ & $\%$ Público & $\%$ Privado & $\%$ Total \\
\hline 1 & $5.0 \%$ & $5.2 \%$ & $2.1 \%$ & $3.3 \%$ \\
2 & $9.4 \%$ & $9.2 \%$ & $4.0 \%$ & $6.0 \%$ \\
3 & $18.6 \%$ & $18.7 \%$ & $11.4 \%$ & $14.2 \%$ \\
4 & $33.1 \%$ & $33.7 \%$ & $26.4 \%$ & $29.2 \%$ \\
Total & $33 .{ }^{*} 9 \%$ & $33.2 \%$ & $56.0 \%$ & $47.3 \%$ \\
Quintiles más bajos & $100.0 \%$ & $100.0 \%$ & $100.0 \%$ & $100.0 \%$ \\
& $14.4 \%$ & $14.5 \%$ & $6.1 \%$ & $9.3 \%$ \\
\hline
\end{tabular}

Fuente: Vélez, Carlos Eduardo. Gasto Social y Desigualdad: Logros y Extravíos. Cuadros 3.6 y 4.1 .10A. Páginas 84y 147.

\footnotetext{
${ }^{36}$ López, H. Op. cit. El traslado de profesores del pregrado al postgrado y a programas de extensión para generar ingresos extra bajo una forma que le permita a la universidad disponer de esos recursos utilizando fundaciones. "Las universidades están trasladando a esas nuevas entidades los ingresos por venta de servicios y dejan en el presupuesto ordinario los gastos laborales que les permiten conseguirlos". p. 11.

${ }^{37}$ Vélez, Carlos Eduardo. Gasto social y desigualdad: logros y extravíos. Santafé de Bogotá: DNP, 1996. La distribución de la matrícula en la educación superior pública en 1992 era: el $40 \%$ más pobre tenía el 18\% de los cupos, mientras el $70 \%$ de los cupos correspondían a los dos quintiles superiores. p. 150. May, Ernesto (Co). La pobreza en Colombia: un estudio del Banco Mundial. Los estratos 4 a 6 reciben el $67 \%$ del subsidio a la educación superior. Además, sólo una cuarta parte de los estudiantes de la educación superior pertenece al $60 \%$ inferior en la distribución del ingreso. p. 66-67.
} 
La gratuidad y la consecuente baja participación del pago de la matrícula en los ingresos totales de la universidad es regresiva también en cuanto debilita la estructura de ingresos de las instituciones $y$, por tanto, limita su capacidad para ampliar cobertura y elevar la calidad de los cupos de la universidad oficial ${ }^{38}$.

En estas condiciones, el sistema de financiación es antimeritocrático, pues en lugar de garantizar a las personas capaces, independientemente de su estrato social, la posibilidad de entrar a la universidad refuerza el peso del filtro ejercido por las condiciones económicas en contra de los miembros más capaces de los estratos de menores ingresos.

\section{Ajustes recientes en los regímenes salariales de pensiones y de cesantías}

Tanto el régimen salarial introducido con la expedición del Decreto 1444, como la imprevisión de las universidades para cubrir sus obligaciones de seguridad social son, claramente, las causas del déficit y, de no eliminarse, tienden a generar un desequilibrio financiero insoluble. Estos son los problemas urgentes que afronta el sector, y que agravaron su crisis financiera: pasivos prestacionales no amparados y ajustes en los regímenes salariales y prestacionales, cuyo saneamiento y homogeneización ha generado costos adicionales importantes.

El sistema de universidades estatales tiene actualmente un pasivo de pensiones y cesantías equivalente a dos veces el costo total de la educación superior pública en 1995. La Ley 30 de 1992 estableció la obligación de sanear los pasivos que por cesantías tienen las universidades estatales y ordenó la adopción del régimen de cesantías definido por la Ley 50 de 1990 para todos los nuevos docentes y para los antiguos que decidieran acogerlo 39 .

Las universidades territoriales tenían en 1994 un pasivo por cesantías de $\$ 89.000$ millones, de los cuales \$62.726 millones correspondían a la nación, la cual giró en 1994 $\$ 25.651$ millones, el saldo fue cubierto a finales de 1996 . El mandato de la ley ${ }^{40}$ no se ha cumplido en lo referente a la participación de las entidades territoriales y de las propias universidades en la financiación de ese pasivo. Por su parte, las universidades del orden nacional no poseían deudas por concepto de cesantías (salvo las universidades de Pereira y de Tunja, a las cuales se les cubrió el pasivo correspondiente).

La Ley de Seguridad Social ordenó el saneamiento del régimen de pensiones en las instituciones de educación superior territorial ${ }^{41}$. Actualmente existen cifras preliminares

\footnotetext{
${ }^{38}$ Es oportuno remitir nuevamente al texto de H. Gómez Buendía (ver arribanota 12), en particular a sus proyecciones acerca de la necesidad de elevar el volumen de recursos captados por concepto del pago de matrículas, para garantizar la expansión de la universidad pública.

${ }^{39}$ Articulo 88 de la Ley 30 de 1992.

${ }^{40}$ Artículo 88.

${ }^{41}$ Artículo 131 de la Ley 100: "Cada una de las instituciones de educación superior oficiales del nivel territorial [...] Constituirá un Fondo para el pago del pasivo pensional contraído a la fecha en la cual esta Ley entre en vigencia (diciembre 23 de 1993), hasta por un monto igual al valor de dicho pasivo que no esté constituido en reservas en las cajas de previsión, o fondos autorizados, descontando el valor actuarial de las futuras cotizaciones que las instituciones como empleadores y los empleados deban efectuar según lo previsto en la presente Ley, en aquella parte que corresponda a funcionarios, empleados o trabajadores vinculados hasta la fecha de iniciación de la vigencia de la presente Ley". "Dicho Fondo se manejará como una subcuenta en el presupuesto de cada institución. Será financiado por la nación, los departamentos, los distritos y los municipios, que aportarán en la misma proporción en que hayan contribuido al presupuesto de la respectiva universidad o institución de educación superior, teniendo en cuenta el promedio de los cinco últimos presupuestos anuales anteriores al año de iniciación de la vigencia de la presente Ley". Los aportes 
acerca de un pasivo pensional de $\$ 1.270$ mil millones de pesos a precios de 1996 . Esta cifra corresponde al faltante que generó el hecho de que las universidades territoriales no tuvieran cajas de pensiones en donde consignar la previsiones de seguridad social, para el pago futuro de las pensiones de los docentes cuyo pasivo se causó a diciembre de 1993. A las universidades nacionales corresponde un porcentaje ínfimo de es pasivo.

De acuerdo con la Ley 100, la nación debe cubrir el porcentaje de pasivo pensional que equivale al promedio de la participación de 1 nación en el presupuesto de las universidades territoriales en lo últimos cinco años. Ese porcentaje ha sido estimado por el Ministerio de Hacienda y Crédito Público en $68.8 \%$ y será cubierto mediante la expedición de bonos pensionales.

Dos graves problemas que tienden a presionar los costos de las universidades públicas son la aplicación del Decreto 1444, que ha venido incrementando de forma irracional el costo de la nómina, y el régimen laboral que permite pensionar a temprana edad a los docentes universitarios de estas instituciones.

El Decreto 1444 de 1992 definió el régimen salarial y prestacional para los docentes de las universidades públicas nacionales, vinculados a partir de la fecha de su expedición y optativo para los ya vinculados. El $97 \%$ de estos docentes de las universidades de carácter nacional se acogieron a dicho régimen. Su introducción generó, en 1993, un costo adicional $\$ 28.576$ millones a precios de 1996 , y un incremento real de $10 \%$ en los sueldos por efecto de la aplicación de la norma mencionada ${ }^{42}$. Para 1996 el régimen del Decreto 1444 se extendió a los restantes docentes con un costo adicional de $\$ 21.837$ millones a precios de 1996, (lo cual representa el 3.8\% de los gastos de funcionamiento para ese año).

En 1994 se dispuso extender las normas contenidas en el Decreto 1444 para abarcar también las universidades territoriales ${ }^{43}$. Para la nación esto tuvo un costo de $\$ 44.254$ millones a precios de 1996 por concepto de cesantías y unificación salarial, cifra que representó aproximadamente el $8 \%$ de los gastos de funcionamiento de ese año. En 1996, al extenderse el régimen del 1444, como resultado del acuerdo entre los docentes y el Ministerio de Educación en 1995, se generó un costo adicional de \$10.033 millones en esas entidades (lo cual representa el $4 \%$ de los gastos de funcionamiento para ese año).

La puesta en marcha del régimen salarial y prestacional contemplado en el Decreto 1444 de 1992, y los importantes incrementos en los costos salariales que ha implicado, no han estado vinculados a mejores resultados en cuanto a la calidad de la educación superior, debido, tanto a las mismas características del decreto como a la forma en que ha sido aplicado. En cuanto al decreto mismo, este define la productividad académica en

constarán de bonos de valor constante de las respectivas entidades que se redimirán a medida que se haga exigible el pago de las obligaciones pensionales, de reglamentación que para el efecto establezca el gobierno nacional".

La suscripción de los bonos, que debió realizarse entre 1993 y 1995, correspondientes al aporte de la nación, tenía como condición actualizar los estudios actuariales con el visto bueno del Ministerio de Hacienda durante 1994. A la fecha en ese ministerio reposa un proyecto de decreto para definir el cubrimiento de este pasivo.

\footnotetext{
${ }^{42}$ Ministerio de Hacienda, Situación presupuestal de las universidades públicas 1990-1996. Documento de trabajo.

${ }^{43}$ Decreto 55. 
forma restringida, limitándola en lo fundamental a las publicaciones efectuadas por los profesores, lo cual no está necesariamente relacionado con un mejoramiento en la calidad de la enseñanza, como tampoco de la investigación y la extensión. De otra parte, en la mayoría de las universidades, especialmente en las de menor calidad, las normas del decreto han sido aplicadas en forma poco rigurosa. En consecuencia, los mayores costos de la universidad pública no se han traducido en mejoramiento de la calidad y la productividad académica.

Por otra parte, el régimen laboral vigente permite que los profesores se pensionen a una edad muy temprana. Un número importante de docentes se pensiona en la etapa de madurez intelectual y mayor producción. Cerca del $50 \%$ de los docentes de las universidades públicas son mayores de 40 años y están próximos a jubilarse, con el agravante de que entre éstos se encuentra una alta producción de los que cuentan con estudios de postgrado en el exterior y de los que más han contribuido al desarrollo de las actividades académicas de las universidades ${ }^{44}$.

En conclusión, la situación actual presenta un régimen laboral docente y una gestión de la seguridad social que presionan los costos de la universidad pública y generan desequilibrios financieros, sin favorecer el mejoramiento de la calidad. Es necesario derogar el Decreto 1444 e introducir un régimen docente más estricto que vincule los aumentos salariales a indicadores de productividad y calidad más sólidos. Así mismo, las universidades y los entes territoriales deben cumplir con las obligaciones establecidas por la Ley 100 en materia de seguridad social, relacionadas con la constitución de fondos pensionales.

\section{Elementos para una propuesta}

La financiación de las instituciones de educación superior ha llegado a una fase en que se impone una búsqueda decidida de la diversidad, tanto de las fuentes, como de los mecanismos y los canales a través de los cuales obtienen recursos estas instituciones. Esa diversidad en la financiación debe conducir a que los actores comprometidos con el destino de la universidad compartan más equitativamente los costos del funcionamiento, expansión y mejoramiento de la calidad de los servicios de la universidad pública.

Hay consenso en que el proceso de asignación negociado e inercial, que actualmente sigue el Estado para asignar recursos, es pobre y tiene efectos negativos. La introducción de un mecanismo normativo que contemple la asignación de recursos basada en la competencia entre las instituciones, de acuerdo con criterios de calidad, productividad, eficiencia y pertinencia es un reto que debe afrontar la educación superior estatal en Colombia en un mareo de autonomía y responsabilidad. Vamos a sugerir algunos elementos que el nuevo ordenamiento podría contener.

\section{Sistema de crédito educativo y financiación de la demanda}

Un elemento central del nuevo esquema sería el sistema de crédito educativo. La porción más importante del gasto público en educación superior debería canalizarse a través del crédito educativo para pago de matrícula y sostenimiento. En lugar de financiar

\footnotetext{
${ }^{44}$ De otra parte, son muy pocos los profesores que están accediendo a programas de formación avanzada. En este sentido es fundamental que el Estado realice un esfuerzo por retener, a través de incentivos, a los docentes próximos a jubilarse y por preparar la generación de relevo, incrementando los recursos destinados a la formación postgraduada en el exterior de los profesores universitarios.
} 
directamente a las universidades, se financiarían a través de créditos educativos que faciliten las condiciones de acceso a la universidad a los estratos socioeconómicos más bajos.

La financiación a la demanda a través del crédito estudiantil estimula la competencia poniendo a prueba la capacidad de las instituciones de atraer estudiantes, capacidad que depende de su credibilidad ${ }^{45}$. Por ello, con el tiempo, los créditos deberían asignarse sólo a estudiantes de programas acreditados.

El sistema de financiación a la demanda aplicaría diferentes criterios de asignación de los créditos. Tendría en cuenta el nivel socioeconómico del estudiante, los méritos académicos del mismo y la orientación hacia las áreas estratégicas del desarrollo del país. Así mismo, la definición del monto de los créditos per cápita estaría en función del grado de complejidad de los programas.

El programa de crédito debe poseer un principio que garantice su no descapitalización. Para ello debe operar una institución financiera, sea esta pública (un banco estatal o el Icetex) o privada, que administre los recursos de crédito, establezca tasas de interés positivas y aplique metodologías eficaces de recuperación de costos.

La recuperación de costos del sistema de crédito depende de la capacidad de pago futura de los egresados. Por ello, deben contemplarse mecanismos de compensación como los subsidios a las tasas de interés y la constitución de un Fondo de Garantías que proteja el capital del sistema de crédito. Así mismo, de acuerdo con el principio de estimular la eficiencia de los agentes del sector de la educación superior, en particular de los estudiantes, se contempla la condonación del crédito por méritos académicos.

Finalmente, el sistema de financiación a la demanda puede constituirse en un mecanismo de direccionamiento de la oferta. En ese sentido podría introducirse un subsidio para estimular la demanda por ciertas áreas académicas que se consideren estratégicas para el país. Como parámetro para la determinación de esas áreas se tomarían en cuenta los lineamientos formulados en los planes de desarrollo económico, social y ambiental del país.

Con esto, se perfila un esquema de financiación de las instituciones de educación superior a través de la demanda, una de cuyas fuentes es el sistema de crédito estudiantil. En esta propuesta, las instituciones perciben un porcentaje importante de sus ingresos por concepto de matrículas y derechos académicos. Actualmente, los recursos provenientes del pago de matrículas financian sólo un poco más del $10 \%$ de los costos totales de las universidades públicas. El objetivo es elevar el nivel de recuperación de costos de operación del pregrado a través del pago de derechos de matrícula. Para evitar el impacto regresivo de esta medida el crédito estudiantil debería orientarse al sector de la población estudiantil perteneciente a los quintiles 1, 2 y 3; mientras que las familias de los quintiles más altos deberían autofinanciar los costos de la educación de sus hijos.

La financiación privada, es decir, la que se da a través de la relación contractual entre un agente privado (el estudiante y las empresas) y una institución que ofrece un servicio,

\footnotetext{
${ }^{45}$ Hugo López propone tres elementos como base de la reforma a la financiación del sector: "estabilizar hacia el futuro y en términos reales los aportes de la nación [...]; financiar mediante crédito educativo y subsidios a la demanda la expansión adicional del sistema público y privado [...]; montar un sistema de información sobre calidad y perspectiva laboral que permita orientar la expansión del sistema hacia las áreas requeridas", op. cit. p. 12.
} 
poco significativa aún en la estructura de ingresos de las universidades estatales, debe ser la fuente principal de ingresos de las universidades públicas, incluso porque su consecución es un signo de pertinencia social de la oferta.

La financiación creciente y gradual del funcionamiento de las universidades a través de la demanda, combinando los programas de crédito estudiantil y becas con los recursos provenientes de las familias le permite al sistema de educación superior oficial en su conjunto recuperar los costos y mantener un flujo de recursos que fortalezca sus posibilidades de expansión y mejore la calidad de la educación ofrecida. Tanto las universidades como los programas de crédito estudiantil y becas pueden conservar su nivel de capitalización gracias a la aplicación de criterios tarifarios selectivos, ajustados a la capacidad de pago de sus usuarios.

El sistema de financiación a la demanda es el instrumento idóneo para una adecuada focalización de los subsidios. Según lo hemos recogido antes, el filtro para el acceso a la educación superior lo constituyen la baja calidad de la educación básica a la que tienen accesos los estratos menos favorecidos ${ }^{46}$ y unas condiciones socioeconómicas que le definen a la alternativa de la formación superior de los grupos familiares más pobres un alto costo de oportunidad. Un programa de becas y créditos subsidiados que cubran, tanto el valor de las matrículas como el sostenimiento estudiantil, e incluso, un margen que compense la expectativa de ingreso familiar puede resolver este problema en forma más eficiente y eficaz que cualquier esquema de subsidio a la oferta.

\section{Nuevos criterios para transferir recursos del gobierno nacional a las universidades públicas}

El aporte directo a las universidades puede asumir, tanto un carácter básico como flexible. La financiación básica estaría destinada garantizar la viabilidad económica de las instituciones, especialmente estabilizando el flujo de recursos para atender las actividades fundamentales. El aporte del Estado, así mismo, asumirla el carácter de una financiación flexible que estimule, de acuerdo con objetivos estratégicos de formación de recursos humanos y de oferta de conocimiento, determinados segmentos de la oferta, por medio de asignaciones para inversión.

Estos dos tipos de financiación deberían fluir a través de esquemas de competencia basados en costos, productividad y calidad. Las decisiones de asignación de recursos deben responder a criterios objetivos de desempeño de las instituciones; y deben enviar señales claras acerca de optimización en el uso de los recursos, generación de ingresos propios, pertinencia de la oferta, calidad, productividad docente e investigativa, ampliación de la cobertura y modernización administrativa.

Al igual que la financiación a través de la demanda, la financiación directa a la oferta debería introducir una simulación del mecanismo de mercado, como forma de sensibilizar la oferta frente a las demandas de la sociedad, los estudiantes y el aparato productivo. La financiación directa, que ya no se destinará a cubrir los costos de operación del pregrado, debe reforzar el carácter competitivo del nuevo esquema de financiación.

Para administrar el esquema de financiación deberla crearse un Fondo de Financiación de la Educación Superior, cuyo órgano de decisión estuviera formado por autoridades

\footnotetext{
${ }^{46}$ En el sector educativo, el Estado colombiano ha dado prioridad a la inversión social en educación básica, tratando de superar el cuello de botella que la cobertura insuficiente y las deficiencias de calidad de este nivel educativo han establecido en contra de los grupos de la población menos favorecidos.
} 
universitarias y representantes del Estado, la academia y el sector productivo. Este fondo tendría como funciones establecer los requerimientos financieros globales del sistema de educación superior, distribuir, de acuerdo con indicadores de desempeño y calidad, los recursos de asignación directa y definir los parámetros de desarrollo del sistema.

A través de este fondo el Estado se convierte en un cliente calificado del sistema de educación superior. La financiación debe adquirir la forma de una transacción contractual por medio de la cual el Estado adquiere bienes académicos e institucionales muy específicos a nombre de la sociedad. Así, estarían operando señales que estimularían la competencia y la coordinación de las instituciones que formen el sistema.

Sin embargo, la incidencia del Estado en la dirección del sistema de educación superior, a través de la financiación, no debe conducir a enajenar a la academia su derecho a determinar el rumbo de las instituciones y del sistema. Los criterios académicos, la lógica y dinamismo particular de la academia deben influir en las decisiones estratégicas de la educación superior. La autonomía financiera tiene que ver, como lo señalamos antes, con la flexibilidad en la ejecución de los recursos y con la exploración de fuentes de financiación diferentes de los aportes de la nación, pero también supone una relación transparente entre los criterios y prioridades del Estado y los criterios académicos y administrativos de las instituciones.

Para eliminar las deficiencias inerciales deberían establecerse cronogramas y condiciones de entrada al sistema, asociadas especialmente a la acreditación. El sistema de educación superior estatal debe ser de élite, desde el punto de vista científico, pedagógico, investigativo y organizacional.

Para cumplir su finalidad, ese fondo debe tener un carácter colegiado, esencialmente académico y no burocrático, y debería garantizar la autonomía y la responsabilidad de las instituciones estatales de educación superior. Esta figura vincularía las decisiones de financiación al control de calidad, la eficiencia y la productividad.

La financiación aplicada por este fondo debe basarse en una regla de capitación. Este elaboraría un portafolio de demanda, estableciendo ponderaciones para las diferentes áreas de estudio, niveles de formación, generación de recursos propios, modalidades y tipos de institución. Con base en esa canasta de demanda evalúa la calidad de las ofertas y su costo, de acuerdo con las categorías del gasto (servicios personales, gastos generales, e inversión en infraestructura básica y dotación), y con indicadores como las relaciones alumno! docente, personal administrativo/docente y productividad, entre otros. Todos estos factores deben conducir a establecer un precio de demanda por estudiante, incorporándose así elementos del modelo de financiación basado en el costo de los insumos ${ }^{47}$.

La financiación básica estaría complementada por recursos de inversión para desarrollo institucional y pedagógico y dotación de equipos. Este fondo asignaría sobre una base competitiva y de acuerdo con indicadores, recursos que ayudarían a encauzar el sistema en una dirección deseada.

\footnotetext{
${ }^{47}$ La experiencia con los modelos de "Input F'unding' ha sido evaluada en diversos países, como Noruega, Suecia, Canadá, Alemania, Reino Unido y Nigeria, entre otros. Es un mecanismo de financiación normativo que proporciona autonomía a las instituciones y envía poderosos incentivos a la eficiencia. Albretch y Ziderman, WBDP 153, capitulo 5.
} 


\section{Estatuto financiero de las universidades públicas}

El Estado debe recuperar la efectividad de sus instrumentos de política en el sector. La forma más eficaz de lograrlo parece ser el diseño y operación de un sistema definido por la autonomía de las instituciones que lo constituyen y por la iniciativa de estas para competir por los recursos financieros. El sistema de educación superior estatal debe poseer la capacidad de crear estructuras de aprendizaje que le permitan ofrecer a la sociedad opciones críticas de reorganización e interpretación de la vida cotidiana, y alternativas de desarrollo de su capacidad productiva; pero el fortalecimiento institucional requerido para ello pasa por la autonomía financiera y, por tanto, por la capacidad para obtener competitivamente los recursos y para explorar opciones de financiación diferentes al aporte fiscal.

El modelo competitivo de financiación que se propone supone instituciones autónomas y con mayor iniciativa. En ese sentido es necesario expedir un estatuto financiero de la universidad pública, que permita darle un manejo flexible y autónomo, acorde con sus funciones fundamentales de docencia, investigación y extensión, y con su naturaleza y misión de largo plazo. El sector requiere un marco normativo semejante al que rige la ciencia y la tecnología. Ese estatuto debe, así mismo, definir una distribución de competencias y obligaciones entre los niveles de la organización territorial y las instituciones estatales de educación superior.

La autonomía financiera es una condición para lograr mayor eficiencia en la asignación de recursos y para aislar a la universidad de la injerencia de criterios ajenos a su naturaleza. Si la universidad puede asignar sus recursos con mayor libertad tendrá mayor capacidad de responder a las oportunidades que el entorno le abra y de corregir ineficiencias en el gasto. Igualmente, se desplazarán desde instancias burocráticas hacia los organismos de dirección legítimos de la universidad decisiones cruciales como las relacionadas con la destinación de los recursos. De paso, la autonomía le hace justicia a las entidades que generan recursos al permitirles disponer de los mismos de acuerdo con la dinámica de sus actividades académicas y de producción de esos recursos.

Obviamente, la autonomía impone responsabilidad. Debería ser claro que una autonomía plena es contraria a la figura de un Estado que deba asumir el papel de un tutor financiero que saque de apuros constantemente a las entidades. Tal situación es insostenible desde el punto de vista de la realidad fiscal, y filosóficamente difícil de defender. Cualquier marco de nuevas reglas de juego debe incluir normas de manejo financiero sano. En este sentido, incrementar los recursos provenientes del pago de matrículas puede ayudar a las instituciones en la gestión financiera sana y en la fundamentación de una autonomía responsable.

El Estado debe asumir un papel de regulador y evaluador de resultados, apoyado en sistemas de acreditación e información en que predominen los criterios de la propia academia y los del beneficio común. Su función debe consistir en la evaluación, basada en indicadores, de las instituciones y del sistema en su conjunto, y no en el ejercicio de un control directo de los procesos. Las instituciones deben gozar de la facultad de asignar y reasignar sus recursos autónomamente.

Por otra parte, un estatuto financiero debe contemplar un régimen laboral y docente más flexible, que incluya incentivos y vincule armónicamente el crecimiento institucional a planes de desarrollo debidamente evaluados, a la capacidad financiera de las instituciones y, en particular, a su capacidad de generación de recursos propios. 


\section{Transición hacia el nuevo modelo}

El esquema propuesto pretende establecer un marco coherente de financiación que estabilice y aumente los recursos del sistema estimulando la iniciativa y autonomía de las instituciones. Sin embargo, la introducción del nuevo esquema de financiamiento tiene como requisito la solución de la crisis actual representada en el pasivo prestacional y en el déficit de funcionamiento de las universidades territoriales. Lo más adecuado sería distribuir entre la nación, los entes territoriales y las universidades el esfuerzo financiero para solucionar la crisis, tal y como lo establecen las leyes de Seguridad Social y de Educación Superior.

\section{Conclusión}

Hemos resaltado en el actual esquema de financiación de la universidad pública dos problemas críticos: los incentivos negativos y la inequidad. La manera cómo se financia la universidad pública no incentiva ni la productividad ni la calidad, de un lado, ni el equilibrio financiero, de otro. Tampoco es eficaz en garantizar el acceso de los grupos de menores ingresos.

La universidad pública ha perdido espacio. Sería ingenuo pensar que la solución de este problema sea simplemente asignar más recursos. Las preguntas fundamentales que debe plantearse el Estado para resolver la actual problemática deben girar en torno a quién merece ser financiado y cómo.

En este artículo se ha esbozado uno de los posibles esquemas de financiación que combinaría financiamiento a la demanda y a la oferta, siempre sobre la base de indicadores de resultados. La financiación a la demanda operaria a través de un sistema de crédito educativo subsidiado, que facilite el acceso de las personas de menores ingresos a la universidad. La financiación a la oferta se basaría en indicadores que estimularan la competencia entre instituciones por los recursos, y estaría mediada por un organismo legítimo de decisión de la universidad pública.

La introducción de medidas de esta naturaleza son aún más urgentes si se considera que, con la sentencia de la Corte Constitucional sobre autonomía ${ }^{48}$ las directivas universitarias pueden asumir que son autónomas para gastar y que en caso de un desbalance en sus finanzas pueden contar con el salvavidas del presupuesto nacional. Es decir, podría formarse la expectativa de que la nación presupuesta el gasto generado y no de acuerdo con los resultados obtenidos. Ello con el agravante de que la Ley 30 de 1992 parece indicar que, cualesquiera sean sus resultados, las universidades deben recibir recursos crecientes del presupuesto nacional.

Sólo cuando las universidades realmente existentes evidencien su compromiso con el concepto de universidad como órgano social de aprendizaje y crítica, y de cultivo de la inteligencia, los valores y la sensibilidad nacionales, los argumentos en contra de la prioridad de su financiamiento perderán su peso. Con la convicción de que el mejor argumento en favor de la financiación de la universidad es la calidad, la propuesta contenida en este documento pretende ser un aporte en la definición del camino hacía esa meta.

\footnotetext{
${ }^{48}$ Sentencia C-220/97 de abril 29 de 1997 
Anexo

El costo por estudiante en las universidades públicas

\begin{tabular}{|c|c|c|c|c|}
\hline Entidades & Costun(1) & Tamaño(2) & Salarpr(3) & Complejl(4) \\
\hline Universidad Nacional & 6.16 & 25.552 & 659.378 & 89 \\
\hline Universidad del Cauca & 4.57 & 5.101 & 675.389 & 75 \\
\hline Universidad Pedagógica Nacional & 4.11 & 4.230 & 657.222 & 49 \\
\hline Universidad de Caldas & 4.80 & 3.653 & 720.704 & 73 \\
\hline Universidad Pedag. y Tecn. de Col. & 3.46 & 7.641 & 799.789 & 63 \\
\hline Universidad de Córdoba & 8.10 & 2.580 & 626.696 & 66 \\
\hline Universidad Tecnológica del Chocó & 4.61 & 1.599 & 680.208 & 55 \\
\hline Universidad Tecn. de los Ilanos Orien. & 3.95 & 1.353 & 709.874 & 65 \\
\hline Universidad Tecnológica de Pereira & 4.62 & 3.530 & 843.126 & 73 \\
\hline Universidad Popular del Cesar & 1.22 & 2.910 & 803.769 & 59 \\
\hline Universidad Surcolombiana de Neiva & 3.03 & 3.226 & 711.06 & 65 \\
\hline Universidad de la Amazonía & 3.54 & 1.049 & 788.669 & 53 \\
\hline Universidad de Antioquia & 3.54 & 18.108 & 785.645 & 83 \\
\hline Universidad del Atlántico & 2.24 & 9.570 & 571.966 & 63 \\
\hline Universidad de Cartagena & 3.34 & 4.638 & 679.270 & 65 \\
\hline Universidad de La Guajira & 2.17 & 1.181 & 574.111 & 67 \\
\hline Universidad de Magdalena & 3.23 & 2.093 & 906.513 & 66 \\
\hline Universidad de Nariño & 2.57 & 4.692 & 833.118 & 60 \\
\hline Universidad Francisco de P. Santander & 1.27 & 5.756 & 569.946 & 61 \\
\hline Universidad de Pamplona & 1.76 & 3.305 & 549.313 & 50 \\
\hline Universidad del Quindío & 1.78 & 7.745 & 713.408 & 56 \\
\hline Universidad Industrial de Santander & 1.65 & 9.726 & 847.373 & 79 \\
\hline Universidad de Sucre & 2.97 & 854 & 634.899 & 60 \\
\hline Universidad del Tolima & 2.61 & 4.573 & 593.703 & 65 \\
\hline Universidad del Valle & 4.64 & 14.255 & 1.009 .618 & 81 \\
\hline $\begin{array}{l}\text { Universidad Distrital FCO. José de } \\
\text { Caldas }\end{array}$ & 3.15 & 7.128 & 651.362 & 73 \\
\hline Universidad de Cundinamarca & 2.48 & 2.252 & 660.853 & 53 \\
\hline Universidad Central del Valle del Cauca & 0.10 & 2.246 & 709.017 & 55 \\
\hline
\end{tabular}

Notas:

(1) Costo por estudiante. Toma el presupuesto total de cada entidad (reportado por Minihacienda) en 1995 y lo divide por el número de estudiantes. Incluye funcionamiento e inversión.

(2) Tamaño. Número de estudiantes. Estadísticas de la educación superior 1995. Matrícula ajustada asignando una ponderación menor a los cupos nocturnos y a distancia.

(3) El salario promedio divide la asignación básica total de la planta de personal por el número total de funcionarios: trabajadores oficiales, personal administrativo y docentes. Fuente Minihacienda - Icfes.

(4) La variable de complejidad 'COMPLEJL' se construye como una suma ponderada de los porcentajes que en la matrícula total de cada entidad tienen las diferentes áreas de pregrado profesional, pedagógico y tecnológico, y los programas de postgrado. Reciben mayor ponderación los programas de ciencias agropecuarias, ingenierías, ciencias y ciencias de la salud, así como los programas de postgrado. A los cupos de la modalidad a distancia se les asigna un menor valor. 